\title{
CD62L Percentage in Peripheral T Cells of Kidney Transplant Recipients Children
}

\author{
Alaa Rashad1, Fatina I. Fadel2, Doaa M. Salah², Eman A. Elghoroury ${ }^{3}$, Neemat M. A. Kassem4, \\ Eman Mahmoud ${ }^{3}$, Mervat Ismail'1, Manal F. Elshamaa' \\ ${ }^{1}$ Department of Pediatrics, National Research Centre, Cairo, Egypt \\ ${ }^{2}$ Department of Pediatrics, Faculty of Medicine, Cairo University, Cairo, Egypt \\ ${ }^{3}$ Departments of Clinical Pathology, National Research Centre, Cairo, Egypt \\ ${ }^{4}$ Oncology Department, Faculty of Medicine, Cairo University, Cairo, Egypt \\ Email: lo2lo2eleslam@hotmail.com
}

How to cite this paper: Rashad, A., Fadel, F.I., Salah, D.M., Elghoroury, E.A., Kassem, N.M.A., Mahmoud, E., Ismail, M. and Elshamaa, M.F. (2021) CD62L Percentage in Peripheral T Cells of Kidney Transplant Recipients Children. Open Journal of Nephrology, 11, 422-436.

https://doi.org/10.4236/ojneph.2021.113035

Received: April 22, 2021

Accepted: September 26, 2021

Published: September 29, 2021

Copyright $\odot 2021$ by author(s) and Scientific Research Publishing Inc. This work is licensed under the Creative Commons Attribution International License (CC BY 4.0).

http://creativecommons.org/licenses/by/4.0/

Open Access

\begin{abstract}
Backgrounds: Recent advances in post Kidney Transplantation (KT) care, have led to a dramatic improvement in short-term outcomes in order to achieve transplantation tolerance; including the ideal tool for clinical monitoring \& new therapeutic line. This study was undertaken to analyze the CD62L in Kidney Transplant Recipients (KTRs) and to investigate its efficacy as a marker of good graft survival. Methods: Fifty pediatric KTRs and 12 healthy controls were included in the study, the frequency of $\mathrm{T}$ cell activation markers; CD62L was measured with flow cytometry after renal transplantation. Clinical, laboratory, immunosuppressive therapy data and graft function of transplant recipients were collected and correlated with their CD62L peripheral blood percentage. Results: The circulating CD62L\% was significantly more in transplant recipients than controls $(44.74 \% \pm 17.45 \%$ vs. $33.36 \% \pm 11.54 \%, \mathrm{p}=0.02) . \mathrm{CD}$ $62 \mathrm{~L} \%$ was more frequent in recipients of living related donors $(\mathrm{p}=0.05)$, positively correlated with donor age $\left(\mathrm{p}=0.04, \mathrm{r}=-0.29^{*}\right)$ and $\mathrm{CD} 4 \%(\mathrm{p}=$ $0.000, r=0.615)$. CD26L $\%$ did not show significant association with acute rejection or chronic rejection $(\mathrm{p}=0.432, \mathrm{p}=0.91$ respectively) or with graft function (serum creatinine or eGFR, $\mathrm{p}=0.086, \mathrm{p}=0.988$ respectively) or immunosuppressive medications. Conclusion: Peripheral CD62L\% is increased after KT than healthy controls, however, it cannot reflect either clinical (serum creatinine and eGFR) or pathological renal graft injury. CD62L surface marker needs more analysis for its potential diagnostic and therapeutic implications as a Treg cell activation marker.
\end{abstract}

\section{Keywords}

CD62L, Regulatory T Cells, Transplantation, Graft Survival, Children 


\section{Introduction}

Recipient's immune status/sensitization, quality of organ, and immunosuppressive treatment are some of the factors that determine graft function and survival after Kidney Transplantation (KT) [1]. Different strategies have been developed in a trial to induce graft tolerance that necessitate better understanding of basic tolerogenic mechanisms as well as the capital role that $\mathrm{T}$ cells play during transplant rejection [2].

Regulatory $\mathrm{T}$ cells (Tregs) have been described as specialized $\mathrm{T}$ lymphocytes that are able to suppress immune responses to self and non-self-antigens and subsequently they mediate tolerance [3]. Tregs have been shown to be important in maintaining immune homeostasis and preventing autoimmune disease, including autoimmune kidney disease. It is also likely that they play a role in limiting kidney transplant rejection and potentially in promoting transplant tolerance [4].

In an attempt to reduce the burden of pharmacologic immunosuppression with subsequent reduction of morbidity and mortality after KT; approaches such as to use biologic therapies in the form of a patient's own immune cells have been developed. These approaches aimed to infuse suppressor immune cells that can selectively impair allograft reactivity rather than globally suppress one's immune system [5].

L-selectin (CD62L) is a glycoprotein and cell adhesion molecule that is expressed on most circulating leukocytes and involved at the stage of leukocyte rolling and tethering to the vascular endothelium including glomerular capillary endothelial cells [6] [7]. Three types of selectins had been identified: P-selectin (platelet selectin), E-selectin (endothelial cell selectin), and L-selectin (leukocyte selectin) [8]. L-selectin regulates entry of naïve and central memory $\mathrm{T}$ cells into lymph nodes and activated $\mathrm{CD}^{+} \mathrm{T}$ cells to sites of inflammation. Down regulation of $\mathrm{L}$-selectin on $\mathrm{T}$ cells is known to take place following engagement of the $\mathrm{T}$-cell receptor, and this has led to $\mathrm{L}$-selectin being used as a marker of $\mathrm{T}$ cell activation.

Therefore, studying CD26L is important from two sides: first, promising an ideal noninvasive, inexpensive, reproducible, and clinician/patient accessible monitoring tool of T cell activation following KT; second, studying CD26L will help to understand the immunobiology of graft rejection with subsequent identifying novel therapeutics.

The recent decade has seen different clinical teams commence and complete first in man clinical trials utilizing Treg cells as an adoptive cellular therapy to achieve tolerance based on understanding immunobiology after transplantation. Those hopeful studies on Treg cell therapy in transplantation could more accurately target the antirejection response and reducing chronic allograft toxicity [9] [10]. However, the understanding of the underlying mechanisms is complicated; because these data differ depending on the species, type of Treg cells, differentiation state and micro-environment [11]. 
In this study we aimed to investigate the recent findings of CD62L\% as noninvasive immunologic monitoring biomarker of graft function and as an indicator of graft survival after KT in pediatrics.

\section{Methods}

\subsection{Patients}

This is a cross sectional case-control that included a total of 50 consecutive pediatric Kidney Transplant Recipients (KTRs). All recipients had ABO-compatible renal transplants and received an allograft at the Centre of Paediatric Nephrology and Transplantation (CPNT), Children's Hospital, Cairo University, Egypt.

Serum creatinine levels were in the range of normal values and there was an absence of hypertension and proteinuria. Subjects were not routinely screened for the development of the novel HLA antibodies post-transplant. Anatomical problems were excluded by ultrasound and nuclear scans. Kidney transplant recipients showing signs of ureteral obstruction and/or renal artery stenosis of the graft, arterial, venous thrombosis, and infection-induced fever were excluded from the study.

Our kind KT pediatric patients were divided into 15 female and 35 males and they were from non-consingouus marriage (74\%). On the other hand, the donor female (28) were more than donor male (22). All patients on HD since the last 9 years, only one patient had previous transplantation, moreover; only 2 patients; had brothers with the same conditions.

Before transplantation; 18 patients had not previously taken antihypertensive drugs but at discharge from hospital after KT, 38 patients had controlled hypertension on double antihypertensive drugs.

All the donors had not medical problem apart from anemia \& controlled HTN; Both donor \& recipient had not blood transfusion diseases (-ve IgG HIV, -ve IgG CMV) \& all were vaccinated against HBV.

Twelve age-Body Mass Index (BMI) and gender-matched healthy children with no clinical signs or family histories of renal disease served as controls. They were recruited from the Pediatric Clinic of Centre of Excellence ${ }^{\odot}$ of the National Research Centre (NRC). The study was taken 18 months from June 2018 to December 2019.

\subsection{Ethical Issues}

The study was approved by the ethical committees of the NRC, and Pediatric Nephrology Unit (PNU), Cairo University Children Hospital, Egypt. Blood samples from patients and control were collected upon written informed consent in accordance with the Declaration of Helsinki.

\subsection{Immunosuppressive (IS) Regimens}

Antibody induction therapy was received by 46 patients, while 4 patients did not receive antibody induction immunosuppression. IL-2 receptor blocking antibo- 
dy (anti-IL-2R Ab, Basiliximab). Anti-Thymocyte Globulin (ATG) [12].

All children received intravenous methylprednisolone perioperative, as a part of induction immunosuppression. Steroids were tapered to oral form a week after transplantation then kept on high dose till the end of the first month. By the first year of transplantation, steroids gradually subsided to oral low dose prednisolone [13].

In addition to steroids; immunosuppressive protocol included calcineurin inhibitor (CNI) and Mycophenolate Mofetil (MMF). MMF was administrated as an adjuvant therapy to all patients for at least 1-month post-transplantation then continued in 46 patients afterward and replaced by evirolimus (Mammalian target of rapamycin inhibitors $)=(\mathrm{mTORI})$, with low CNI dose in 4 patients. The initial dose of MMF was 360 - $1440 \mathrm{mg} /$ day, and the dose was modified based on adverse effects such as diarrhea or leucopenia [14].

\subsection{Clinical Parameters}

The potential factors which may affect surface marker CD62L were included. The number of HLA mismatch (out of 6 HLA alleles for the 3 assessed HLA classes; HLA class A, HLA class B, HLA class DR), donor relation (related vs. unrelated), episode of cytomegalovirus (CMV) infection, graft function (in term of serum creatinine and calculated Glomerular Filtration Rate (eGFR)) and CNI trough levels at assessment were evaluated.

Cold ischemia time was defined as the time elapsed between clamping of the donor graft artery and de-clamping of the anastomosing vessel in the recipient (signifies the duration of ischemia/reperfusion injury). Acute Rejection (AR) was defined as a rise in serum creatinine of $20 \%-30 \%$ from baseline levels and accompanied by clinical symptoms and signs as fever, graft tenderness, and oliguria [15]. Presumed Acute Rejection (PRAR) was defined as an episode of AR, which is diagnosed clinically and treated by pulse methylprednisolone, however a biopsy the sample was not taken or did not have the signs of rejection according to the Banff-criteria [16]. Biopsy-Proven Acute Rejection (BPAR) was defined as acute graft dysfunction accompanied by pathological evidence of rejection.

Chronic Allograft Dysfunction (CAD) was defined clinically as a progressive decline of graft function with $\geq 15 \%$ irreversible increase in creatinine level within 1 to 3 months and proteinuria $\geq 1 \mathrm{~g} / 24 \mathrm{~h}$ accompanied with a pathological diagnosis of Interstitial Fibrosis and Tubular Atrophy (IFTA) [17].

\subsection{Flow Cytometric Analysis}

Peripheral blood samples were obtained in Healthy Controls (HCs) and KTRs. Blood samples were withdrawn $30.94 \pm 16.51$ month after transplantation in KTRs. Patients with AR had their samples withdrawn when they achieved stable graft function (after rejection episode has been treated by antirejection therapy). Fresh blood samples on EDTA (100 ul) with monoclonal antibodies were incubated $20^{\prime}$ in the room temperature in the dark. Samples were lysed with $0.5 \mathrm{ml}$ lysing solution Optilyse C (Beckman Coulter, Brea, CA, USA) 10' the room 
temperature in the dark. Lysing reaction was stopped with $1 \mathrm{ml}$ Cell Wash (optimized PBS) (Beckton Dickinson Bioscience, Benelux, Belgium), the pellet suspended in PBS and kept in dark between $2^{\circ} \mathrm{C}-8^{\circ} \mathrm{C}$. Samples were measured on a FC 500 flow cytometer (Beckman Coulter, Brea, CA, USA). Gating strategy: As described before cells were gated by side scatter and CD4 expression. Subsequently CD62L was measured on the cell surfaces. A flow cytometry analysis was performed with at least 100 events in the gate.

\subsection{Statistical Analysis}

Statistical analysis of data was done by using SPSS version 16.0. Chi-Square test was used for comparison between data presented as frequency and percentage. The student $t$-test was used for comparison between data presented as mean and Standard Deviation (SD). Correlation between various variables was done using the Spearman rank correlation equation. Nonparametric data were compared using Mann-Whitney and Kruskal-Wallis Tests. ANOVA Post Hoc Test was used for multiple comparisons. Sample size was measured to be 45 or more to have a confidence level of $95 \%$ that the real value is within $\pm 5 \%$ of the measured/surveyed value with a calculated power of the study about $80 \%$ [18]. A p value of $<0.05$ was considered statistically significant.

\section{Results}

Demographics, clinical \& laboratory parameters of KTRs and HCs and their correlations with CD62L\% are summarized in Table 1. The original renal disease of KTRs was obstructive uropathy in 18 patients (36\%), inherited nephropathy in 14 patients (28\%), unknown in 14 patients (28\%), and chronic glomerulopathy in 4 patients (8\%). The mean CD62L\% of transplanted patients was significantly elevated than that of controls ( $44.74 \pm 17.45$ vs. $33.36 \pm 11.54, p=0.02)$ (Figure 1). Box plot and Whisker of CD62L\% expression in cases and controls are shown in Figure 2 and Figure 3.

The means of CD62L\% expression

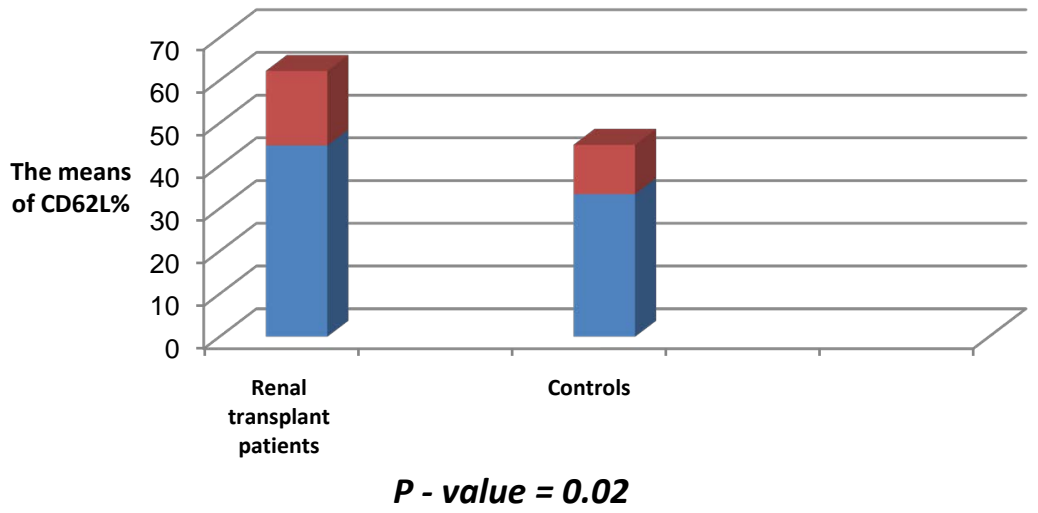

Figure 1. The mean CD62L\% expression of transplanted patients was significantly elevated than that of controls $(44.74 \pm 17.45$ vs. $33.36 \pm 11.54, \mathrm{p}=0.02)$. 
Table 1. The demographics clinical \& laboratory data of the cases \& controls and correlations of data to CD62L\%.

\begin{tabular}{|c|c|c|c|c|c|}
\hline & Patients $(n=50)$ & Controls $(n=12)$ & P-Value & CD62L p-value & $\begin{array}{c}\text { CD62L correlation } \\
\text { coefficient }\end{array}$ \\
\hline Age at KT (years) & $10.36 \pm 3.84$ & ------- & ------- & 0.32 & -0.15 \\
\hline Age at assessment (years) & $12.94 \pm 4.23$ & $10.7 \pm 4.51$ & 0.132 & 0.34 & -0.14 \\
\hline $\operatorname{Sex}(M / F)$ & $35 / 15(70 \% / 30 \%)$ & $8 / 4(66.7 \% / 33.3 \%)$ & 0.123 & -------- & ------- \\
\hline Post transplantation FU duration (mo) & $30.94 \pm 16.51$ & -------- & ------- & 0.69 & 0.06 \\
\hline Dialysis duration (mo) & $21.70 \pm 25.34$ & ------- & ------- & 0.12 & -0.23 \\
\hline $\mathrm{BMI}\left(\mathrm{Kg} / \mathrm{m}^{2}\right)$ & $22.63 \pm 7.88$ & $23.60 \pm 8.44$ & 0.859 & 0.36 & -0.22 \\
\hline SBP (mmHg) & $109.40 \pm 10.50$ & $95.54 \pm 9.70$ & 0.0001 & 0.95 & 0.01 \\
\hline $\mathrm{DBP}(\mathrm{mmHg})$ & $70.40 \pm 8.91$ & $61.55 \pm 10.10$ & 0.0001 & 0.29 & 0.152 \\
\hline Donor Age (years) & $37.18 \pm 6.21$ & -------- & ------- & 0.04 & $-0.29^{*}$ \\
\hline Number of mismatch/6 & $2.5 \pm 0.77$ & -------- & -------- & 0.033 & $0.305^{*}$ \\
\hline Cold ischemia time (minutes) & $52.45 \pm 12.30$ & -------- & -------- & 0.11 & -0.24 \\
\hline PRD dose at $1 \mathrm{mo}$ (mg/day) & $19.02 \pm 5.44$ & -------- & ------- & 0.43 & 0.12 \\
\hline PRD dose at $12 \mathrm{mo}$ (mg/day) & $4.23 \pm 1.55$ & -------- & ------- & 0.12 & -0.23 \\
\hline Trough CsA level (ng/ml) & $110.83 \pm 18.55$ & ------- & ------- & 0.62 & 0.26 \\
\hline Trough tacrolimus (ng/ml) & $6.26 \pm 1.16$ & ------- & ------- & 0.93 & 0.02 \\
\hline Serum creatinin $(\mathrm{mg} / \mathrm{dl})$ & $1.53 \pm 3.01$ & ------- & ------- & 0.086 & -0.250 \\
\hline eGFR $\left(\mathrm{ml} / \mathrm{min} / 1.73 \mathrm{~m}^{2}\right)$ & $76.20 \pm 22.10$ & $96 \pm 18.8$ & 0.0203 & 0.988 & -.002 \\
\hline $\mathrm{HB}(\mathrm{gm} / \mathrm{dl})$ & $10.84 \pm 1.17$ & $14.23 \pm 1.50$ & $<0.0001$ & 0.83 & -0.04 \\
\hline HCT & $32.14 \pm 4.20$ & $38.88 \pm 3.62$ & 0.0001 & 0.34 & -0.17 \\
\hline $\operatorname{TLC}\left[\times 10^{3} / \mathrm{mm}^{-3}\right]$ & $7.83 \pm 2.61$ & $3.57 \pm 1.42$ & $<0.0001$ & 0.68 & 0.07 \\
\hline G count $\left[\times 10^{3} / \mathrm{mm}^{-3}\right]$ & $49.70 \pm 17.15$ & 42.42 .12 .32 & 0.0181 & 0.74 & 0.06 \\
\hline $\mathrm{L}$ count $\left[\times 10^{3} / \mathrm{mm}^{-3}\right]$ & $37.07 \pm 16.64$ & $22.20 \pm 15.21$ & $<0.0001$ & 0.83 & -0.04 \\
\hline PLT $\left[\times 10^{3} / \mathrm{mm}^{-3}\right]$ & $223.06 \pm 78.41$ & $269.45 \pm 84.02$ & 0.0057 & 0.36 & 0.162 \\
\hline CD $4 \%$ & $34.32 \pm 9.58$ & $34.78 \pm 10.01$ & 0.882 & 0.0001 & 0.615 \\
\hline CD62L\% & $44.74 \pm 17.45$ & $33.36 \pm 11.54$ & 0.02 & ------ & ------- \\
\hline
\end{tabular}

KT (kidney transplantation), FU (follow up), BMI (body mass index), SBP (systolic blood pressure), DBP (diastolic blood pressure), PRD (prednisolone), CsA (cyclosporine), HB (hemoglobin), eGFR (estimated glomerular filtration rate), HCT (hematocrit), MCV (mean corpuscular volume), MCH (mean corpuscular hemoglobin), MCHC (mean corpuscularhemoglobin concentration), TLC (total leucocyte count), G (granulocyte count), L (lymphocyte count), PLT (platelet count). ${ }^{*} \mathrm{P}<0.05$ was considered significant.

No significant difference was detected between KTRs and HCs as regard $\mathrm{CD} 4 \%(34.32 \pm 9.58$ vs $34.78 \pm 10.01, \mathrm{p}=0.822)$. Correlations between CD62L\% and different clinical/transplantation related data revealed significant negative correlation of $\mathrm{CD} 62 \mathrm{~L} \%$ with donor age $(\mathrm{P}=0.04, \mathrm{CC}=0.29)$ (Figure 4$)$ and significant positive correlation of CD62L\% with number of HLA mismatches between donors and recipients $(\mathrm{P}=0.033, \mathrm{CC}=0.305)$ (Figure 5). $\mathrm{CD} 62 \mathrm{~L}$ did not correlate with any of maintenance immunosuppressive therapy type or dose (Table 1). No significant correlations were detected between CD62L\% and other laboratory parameters except for positive correlation with CD $4 \%(\mathrm{p}=0.0001$, $\mathrm{CC}=0.615)$ (Figure 6). 
Box plot of cases

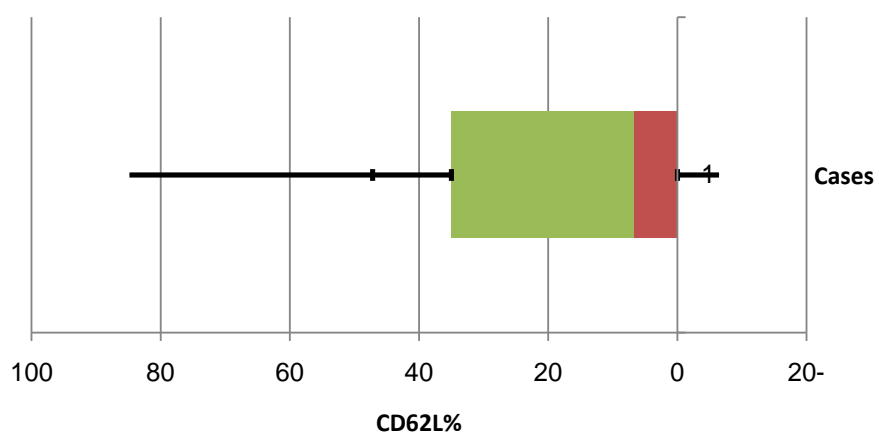

Figure 2. Box plot of CD62L\% expression of transplanted patients.

Box plot of controls

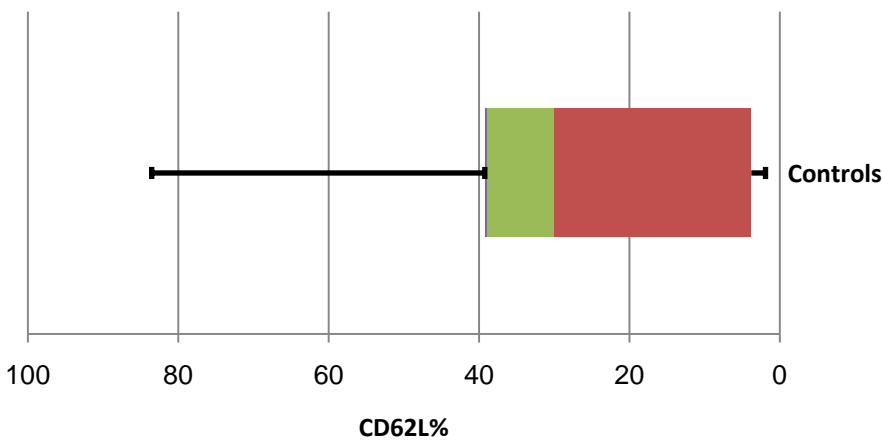

Figure 3. Box plot of CD62L\% expression of controls.

CD62L\% \& Donor age $(P$-Value $=0.04)$

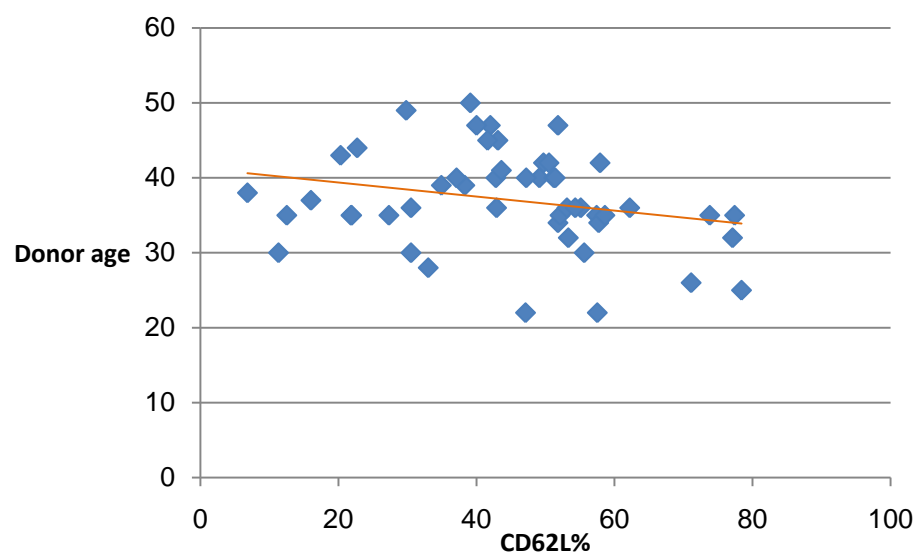

Figure 4. CD62L\% expression was significantly correlated with the donor age (p-value = $0.04)$.

As illustrated in Table 2; donor relations are showed significant association with CD62L\% (41.85\% $\pm 16.73 \%$ vs. $53.64 \pm 17.28$ in related vs nonrelated donor KTRs, $\mathrm{p}=0.051$ ). Subgrouping of KTRs according to their CMV status, immunosuppression medications, AR episodes (either PRAR or BPAR) did not show significant association with CD62L\%. 


\section{CD62L\% \& NO of mismatch}

(P-Value $=0.033)$

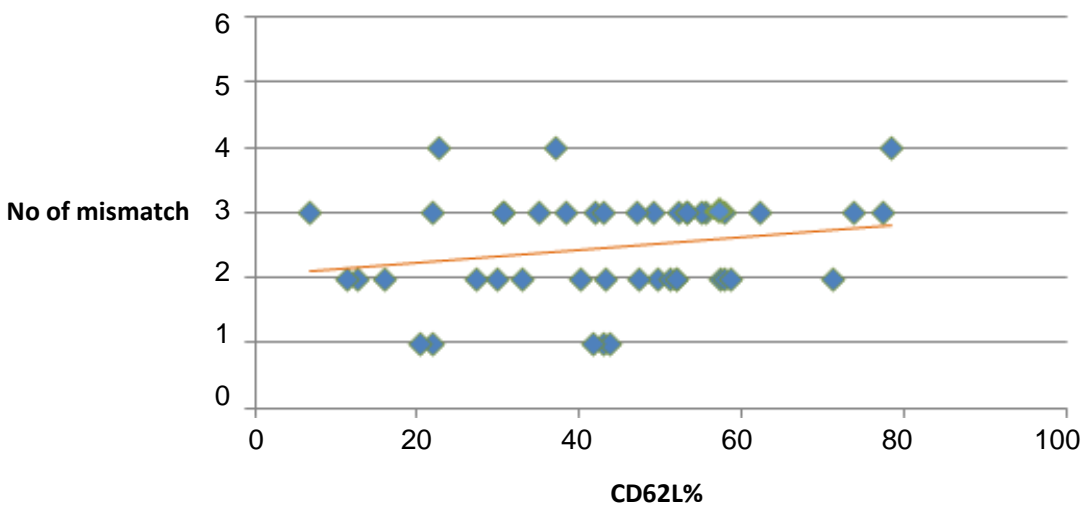

Figure 5. CD62L\% expression was significantly correlated with the no of mismatch ( $\mathrm{p}$ value $=0.033$.

\section{Correlation between CD62L\% \& CD4 $P$-value $=0.0001$}

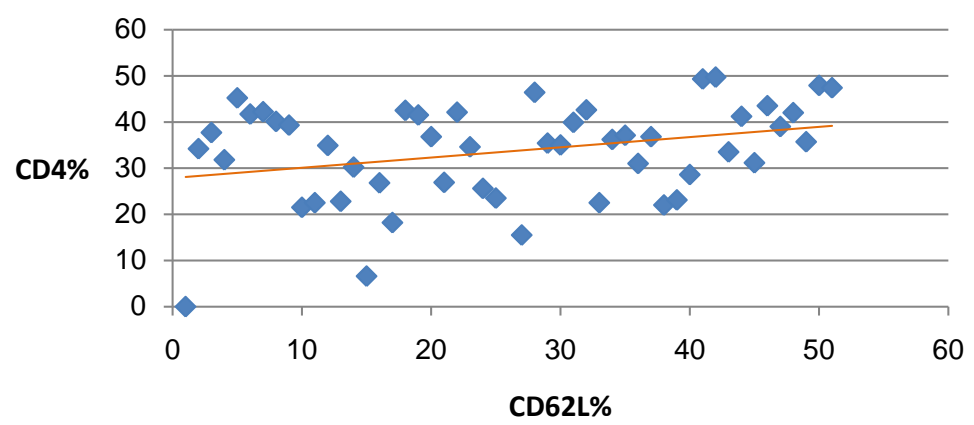

Figure 6. CD62L\% expression was significantly correlated with CD4\% (p-value $=0.0001)$.

Table 2. Comparisons of the lymphocyte surface marker (CD62L) with different subgroups of transplanted patients $(n=50)$.

\begin{tabular}{ccc}
\hline & (Mean \pm SD) CD62L & p value \\
\hline Donor relation & & \\
Related donor $(\mathrm{n}=37)$ & $41.85 \pm 16.73$ & 0.051 \\
Nonrelated donors $(\mathrm{n}=12)$ & $53.64 \pm 17.28$ & \\
Antibody induction therapy & & \\
ATG $(\mathrm{n}=34)$ & $42.25 \pm 18.14$ & \\
Basiliximab $(\mathrm{n}=12)$ & $42.28 \pm 13.60$ & \\
No antibody induction $(\mathrm{n}=4)$ & $62.40 \pm 15.40$ & \\
Immunosuppression protocol & & \\
CsA based protocol $(\mathrm{n}=14)$ & $48.15 \pm 15.56$ & \\
Tacrolimus based protocol $(\mathrm{n}=32)$ & $43.76 \pm 18.56$ & \\
m-TORI low CsA protocol $(\mathrm{n}=4)$ & $30.50 \pm 11.03$ & \\
\hline
\end{tabular}




\section{Continued}

\begin{tabular}{ccc} 
CNI used & & \\
CsA $(\mathrm{n}=17)$ & $48.15 \pm 15.56$ & \\
Tacrolimus $(\mathrm{n}=32)$ & $42.93 \pm 18.35$ & \\
CMV status & & 0.326 \\
CMV RT-PCR -ve $(\mathrm{n}=40)$ & $45.85 \pm 18.08$ & \\
CMV RT-PCR +ve $(\mathrm{n}=10)$ & $39.81 \pm 14.12$ & \\
Previous PRAR episodes & & \\
No PRAR $(\mathrm{n}=16)$ & $45.46 \pm 15.26$ \\
1episode PRAR ( $\mathrm{n}=9)$ & $43.82 \pm 20.36$ & \\
$\geq 2$ episodes PRAR $(\mathrm{n}=25)$ & $44.60 \pm 18.41$ & 0.430 \\
Previous BPAR episodes & & \\
No BPAR $(\mathrm{n}=16)$ & $40.79 \pm 21.71$ & \\
Yes BPAR $(\mathrm{n}=33)$ & $46.65 \pm 14.98$ & \\
Pathological evidence of CAD & & \\
No CAD $(\mathrm{n}=43$ & $44.76 \pm 16.26$ & \\
Yes CAD $(\mathrm{n}=7)$ & $44.63 \pm 25.07$ & \\
\hline
\end{tabular}

ATG (anti-thymocyte globulin), IS (immunosuppression), CNI (calcineurin inhibitor), CsA (cyclosporine), mTORI (mammalian target of rapamycin inhibitors), CMV (cytomegalovirus) RT-PCR (Real time-polymerase chain reaction), PRAR (presumed acute rejection), BPAR (biopsy proven acute rejection), CAD (chronic allograft dysfunction). $\mathrm{P}<0.05$ was considered significant.

No significant difference was found in CD62L\% in different antibody induction therapy groups (ATG group, $42.25 \% \pm 18.14 \%$ vs Basiliximab group, $42.28 \%$ $\pm 13.60 \%$ vs. no antibody induction group $62.40 \% \pm 15.40 \%, \mathrm{p}=0.172$ ).

No significant difference was found in CD62L\% on comparing BPAR episodes cases vs. cases with no PRAR episode ( $46.65 \pm 14.98$ vs. $40.79 \pm 21.71, \mathrm{p}=0.432)$. Also, no significant difference was found in CD62L\% on comparing patients with CAD vs. patients with no CAD $(44.63 \pm 25.07$ vs. $44.76 \pm 16.26, \mathrm{p}=0.91)$.

\section{Discussion}

In the present study, we tried to analyze the expression CD62L, as a marker of $\mathrm{T}$ cell activation, in pediatric KTRs and to evaluate its relation to different clinical, laboratory and therapeutic variables. The key clinical questions raised by this study are: whether $\mathrm{CD} 26 \mathrm{~L}$ deserves more advanced research as a parameter of immunologic monitoring in KTRs? Is it affected by dose/type of the immunosuppressant drugs? Does CD62L\% non-invasively reflects pathological graft injury (as in BPAR and IFTA in CAD) with subsequent correlation with graft function and prediction of future graft survival? Answers of these questions do not only offer a potential non-invasive immunological marker but also open the gate for future therapeutic interventions.

Results of the present study demonstrated that CD62L\% has a significant in- 
creased frequency in pediatric KTRs than matched HCs. Our finding was supported by previous studies on immunosuppressed population. CD26L was reported to be a functional marker of innate lymphoid cells precursors (ILCP), and has the potential to be used as a diagnostic marker in inflammatory or autoimmune disorders [19]. Additionally; CD62L was found to present in peripheral blood of patients suffering from a range of immune-mediated diseases when compared with healthy individuals [20] [21] [22] [23].

In the present study; a significant positive correlation was demonstrated between the surface marker CD26L and CD4. Our finding is going with what was reported by Tang and his colleagues around two decades ago. They found that surface CD62L expression is critical for efficient $\mathrm{CD} 4+\mathrm{T}$ cell recirculation and that high levels of surface CD62L on CD62L+CD4+ T cells in young mice confer the ability to recirculate efficiently [24]. Few years later; Yang et al. confirmed this finding; they worked on knockout models and showed that a $50 \%$ decrease in CD62L results in a 50\% - 70\% decrease in T cell recirculation efficiency [25].

Results of the present study revealed that the frequency of circulating CD62L has no significant association with recipient related demographic and clinical parameters (in term of age, sex, dialysis/post-transplantation durations, BMI and blood pressure).

We reported, however, CD62L significantly negatively correlates with donor age $(\mathrm{P}=0.04, \mathrm{CC}=-0.29)$ and positively correlates with number of donor/recipient HLA mismatches $(\mathrm{P}=0.033, \mathrm{CC}=0.305)$.

CD62L has been identified as one of the $\mathrm{T}$ regs novel subpopulations [26]. This has been studied further by other teams in a range of transplant-related (renal/liver) and non-transplant-related settings [10].

Unlike our findings; Krajewska, et al. showed a negative correlation between the recipient age and Treg population following KT [1]. Donor/recipient age mismatch in our study is an inevitable confounding factor, since our pediatric population received only adult living renal graft based on national regulations. Deficiency of pediatric reports analyzing $\mathrm{T}$ regs made it mandatory to use adult references.

Different opinion from other studies in adult KT have reported a relatively potential positive effect in patient or graft survival outcomes derived from age matching between donors and recipient [27] [28] [29] [30].

To the best of our knowledge, this is the first study that correlates $\mathrm{T}$ regs to donor rather than recipient age. The prevalence of more CD62L $\mathrm{T}$ regs among KTRs of younger rather than older grafts may direct future researches towards investigating role of donor age in tolerance after KT. Chiu et al., showed that that the level of surface $\mathrm{CD} 62 \mathrm{~L}$ on the $\mathrm{CD} 62 \mathrm{~L}+\mathrm{CD} 4+\mathrm{T}$ cell subset decreases progressively with age, such that by 24 months there is a $50 \%$ decrease in surface CD62L level and a 70\% decrease in recirculation efficiency [31]. Nevertheless; this still cannot explain our finding since the tested CD62L were circulating recipient subset not in situ graft cells. 
The present study could not report any significant association between CD62L expression and any of immunosuppressive therapy type or dose.

The impact of immunosuppressants on different $\mathrm{T}$ cell subsets remains unclear [32]. Share this opinion; Nasimudeen, et al., concluded that the Immunosuppression with tacrolimus or sirolimus based regimens did not influence the Treg cell levels. The regulatory $\mathrm{T}$ cell levels in patients on these regimens were similar to the HCs [33].

Our previously published report of lymphocyte activation markers in pediatric $\mathrm{KT}$ revealed that the frequency of circulating Treg cell is significantly reduced by CNI [3]. Also, previous studies, demonstrated the efficacy of CNI to have a deleterious effect on Treg cells, both in vitro and in vivo. Moreover, serum level of tacrolimus was found to be inversely correlated with Treg frequency in patients with AR, suggesting that rejectors may be more susceptible to tacrolimus induced Treg apoptosis [34]. Others found that $\mathrm{CD}_{2} \mathrm{~L}^{+}$expression is altered in patients treated with different disease-modifying therapies when measured in freshly collected samples [35]. mTOR inhibitors have been shown to promote the differentiation and expansion of Tregs [36] [37]. With our small sample size and owing to the fact that all our patients received CNIs, with only 4 patients received $m$ TOR inhibitors, it was difficult to evaluate the influence of immunosuppressant separately on circulating CD62L\% by the present study.

The results of our study demonstrate that the frequency of circulating CD62L is not significantly associated with previous episodes of acute graft injury (PRAR, BPAR) or ongoing chronic graft injury (CAD). CD62L does not also show significant association with graft function at assessment (in term of serum creatinine and eGFR) according to our results. Although our findings did not support the role of $\mathrm{CD} 62 \mathrm{~L}$ as a marker reflecting neither pathological nor clinical graft injury, the cross sectional nature of the study limited these results.

CD4 population of Treg have emerged as a promising candidate therapy that may allow transplant recipients to retain a long-term functioning allograft by induction of tolerance (no immunosuppression), or prop tolerance (minimal immunosuppression) [37]. Therapeutic implications of Treg cells have been recently addressed by Atif, et al., They discussed different clinical teams commence and complete first in man clinical trials utilizing Treg cells as an adoptive cellular therapy in solid organ transplantation (8 trial in liver transplantation and 10 in KT from different countries) [10]. One of them, TRACT trial from North western University (Chicago, USA), utilized ex vivo expanded polyclonal Treg cells infused in into 9 living donors transplant recipients. This trial focused on the expression of Treg cells markers of function (included CD62L), all functional markers were significantly increased post expansion. Notably; they did not report cases of opportunistic infections or rejection [38]. The next step will be to demonstrate the in vivo survival and function of these Treg cells.

The present study has a number of limitations including small sample size, cross sectional analysis of KTRs, the uniform use of CNI in included patients and lack of correlation of the target surface marker CD62L with detailed patho- 
logical data or long term graft outcome on 5 and 10 year follow up. These limitations can be overcome by further studies analyzing CD62L in the setting of active $\mathrm{AR}$, on determined periods after $\mathrm{KT}$ and with large number of pediatric KTRs.

Before conducting the study; we hypothesized that CD62L+ T cells in peripheral blood of KTRs might serve as noninvasive immunologic monitoring biomarker of renal graft and as an indicator of graft survival. Our hypothesis was based on role of CD62L as a Treg cell functional activation marker. Although our results did not fully support the proposed hypothesis; studies focusing on the number of effectors memory $\mathrm{T}$ cells, and central memory $\mathrm{T}$ cells assessment which helps in understanding the efficacy CD62L on renal transplant are highly recommended, to determine the number of Tregs necessary to achieve tolerance, more important than the total dose administered.

\section{Conclusions}

Peripheral CD62L\% surface marker is increased after KT than healthy controls, however, it cannot reflect either clinical (serum creatinine and eGFR) or pathological (PRAR, BPAR or CAN) renal graft injury in the pediatric population after KT.

CD62L surface marker is correlated positively with CD4 cells being a subgroup of them and negatively with living donor age, a finding that needs further research. CD62L\% T cells are more in KTRs of living related than living non-related donor reflecting more adaptive immunity with living related KT. The present study failed to demonstrate a relation between CD62L and immunotherapy, but this should not discourage further researches to characterize these cells and bring to light the molecular factors and signaling pathways that play a major role in graft tolerance.

\section{Conflicts of Interest}

The authors declare no conflicts of interest regarding the publication of this paper.

\section{References}

[1] Krajewska, M., Kościelska-Kasprzak, K., Kamińska, D., Żabińska, M., Myszka-Kozłowska, M., Gomułkiewicz, A., Dzięgiel, P. and Klinger, M. (2019) Kidney Transplant Outcome Is Associated with Regulatory T Cell Population and Gene Expression Early after Transplantation. Journal of Immunology Research, 2019, Article ID: 7452019. https://doi.org/10.1155/2019/7452019

[2] Bestard, O., Cruzado, J.M., Mestre, M., Caldés, A., et al. (2007) Achieving Donor-Specific Hyporesponsiveness Is Associated with FOXP3+ Regulatory T Cell Recruitment in Human Renal Allograft Infiltrates. The Journal of Immunology, 179, 4901 4909. https://doi.org/10.4049/jimmunol.179.7.4901

[3] Fadel, F.I., Elghoroury, E.A., Elshamaa, M.F., Bazaraa, H.M., Salah, D.M., Kassem, N.M.A., Ibrahim, M.H., El-Saaid, G.S., Nasr, S.A. and Koura, H.M. (2015) Lymphocyte Activation Markers in Pediatric Kidney Transplant Recipients. International 
Journal of Biomedical Science, 11, 121-130.

[4] Hu, M., Wang, Y.M., Wang, Y., Zhang, G.Z., Zheng, G., Shounan, Y., O'Connell, P.J.O., Harris, D.C.H. and Alexander, S.I. (2016) Regulatory T Cells in Kidney Disease and Transplantation. Kidney International, 90, 502-514.

https://doi.org/10.1016/j.kint.2016.03.022

[5] Zwang, N.A. and Leventhal, J.R. (2017) Cell Therapy in Kidney Transplantation: Focus on Regulatory T Cells. Journal of the American Society of Nephrology, 28, 19601972. https://doi.org/10.1681/ASN.2016111206

[6] Ivetic, A., Green, H.L.G. and Hart, S.J. (2019) L-Selectin: A Major Regulator of Leukocyte Adhesion, Migration and Signaling. Frontiers in Immunology, 10, 1068. https://doi.org/10.3389/fimmu.2019.01068

[7] McLaren, A.J., Marshall, S.E., Haldar, N.A., Mullighan, C.G., Fuggle, S.V., Morris, P.J. and Welsh, K.I. (1999) Adhesion Molecule Polymorphisms in Chronic Renal Allograft Failure. Kidney International, 55, 1977-1982.

https://doi.org/10.1046/j.1523-1755.1999.00427.x

[8] Zarbock, A., Ley, K., McEver, R.P. and Hidalgo, A. (2011) Leukocyte Ligands for Endothelial Selectins: Specialized Glycoconjugates That Mediate Rolling and Signaling under Flow. Blood, 118, 6743-6751.

https://doi.org/10.1182/blood-2011-07-343566

[9] Townamchai, N., Safa, K. and Chandraker, A. (2013) Immunologic Monitoring in Kidney Transplant Recipients. Kidney Research and Clinical Practice, 32, 52-61. https://doi.org/10.1016/j.krcp.2013.04.002

[10] Atif, M., Conti, F., Gorochov, G., Oo, Y.H. and Miyara, M. (2020) Regulatory T Cells in Solid Organ Transplantation. Clinical \& Translational Immunology, 9, e01099. https://doi.org/10.1002/cti2.1099

[11] Kanamori, M., Nakatsukasa, H., Okada, M., et al. (2016) Induced Regulatory T Cells: Their Development, Stability, and Applications. Trends in Immunology, 37, 803-811. https://doi.org/10.1016/j.it.2016.08.012

[12] Yang, S.L., Wang, D., Wu, W.Z., Lin, W.H., Xu, T.Z., Cai, J.Q. and Tan, J.M. (2008) Comparison of Single Bolus ATG and Basiliximab as Induction Therapy in Presensitized Renal Allograft Recipients Receiving Tacrolimus-Based Immunosuppressive Regimen. Transplant Immunology, 18, 281-285. https://doi.org/10.1016/j.trim.2007.08.002

[13] Steiner, R.W. and Awdishu, L. (2011) Steroids in Kidney Transplant Patients. Seminars in Immunopathology, 33, 157-167. https://doi.org/10.1007/s00281-011-0259-7

[14] Chelala, D.N., Mourani, C., Moukarzel, M. and Azar, H. (2015) Immunosuppressive Protocols in Kidney Transplantation: With or without Induction? Journal Medical Libanais, 63, 150-153. https://doi.org/10.12816/0015838

[15] Huang, P.C., Yang, C.Y., Lee, C.Y., Yeh, C.C., et al. (2013) Pediatric Renal Transplantation: Results and Prognostic Factors. Asian Journal of Surgery, 36, 53-57. https://doi.org/10.1016/j.asjsur.2012.09.001

[16] Fleiner, F., Fritsche, L., Glander, P., Neumayer, H.H. and Budde, K. (2006) Reporting of Rejection after Renal Transplantation in Large Immunosuppressive Trials: Biopsy-Proven, Clinical, Presumed, or Treated Rejection? Transplantation, 81, 655-659. https://doi.org/10.1097/01.tp.0000214933.73927.4e

[17] Chapman, J.R., O'Connell, P.J. and Nankivell, B.J. (2005) Chronic Renal Allograft Dysfunction. Journal of the American Society of Nephrology, 16, 3015-3026. https://doi.org/10.1681/ASN.2005050463 
[18] Suresh, K.P. and Chandrashekara, S. (2012) Sample Size Estimation and Power Analysis for Clinical Research Studies. Journal of Human Reproductive Sciences, 5, 7-13. https://doi.org/10.4103/0974-1208.97779

[19] Bar-Ephraim, Y.E., Koning, J.J., Ruiz, E.B., Konijn, T., Mourits, V.P., Lakeman, K.M. et al. (2019) CD62L Is a Functional and Phenotypic Marker for Circulating Innate Lymphoid Cell Precursors. Journal of Immunology, 202, 171-182. https://doi.org/10.4049/jimmunol.1701153

[20] Bjorklund, A.K., Forkel, M., Picelli, S., Konya, V., Theorell, V., Friberg, D., Sandberg, R. and Mjosberg, J. (2016) The Heterogeneity of Human CD127 Innate Lymphoid Cells Revealed by Single-Cell RNA Sequencing. Nature Immunology, 17, 451-460. https://doi.org/10.1038/ni.3368

[21] Illanova, F., Flutter, B., Tosi, I., Grys, K., Sreeneebus, H., Perera, G.K., Chapman, A., Smith, C.H., Meglio, P.D. and Nestle, F.O. (2014) Characterization of Innate Lymphoid Cells in Human Skin and Blood Demonstrates Increase of NKp44+ ILC3 in Psoriasis. Journal of Investigative Dermatology, 134, 984-991.

https://doi.org/10.1038/jid.2013.477

[22] Teunissen, M.B.M., Munneke, J.M., Bernink, J.H., Spuls, P.I., Res, P.C.M., Velde, A.T., Cheuk, S., Brouwer, M.W.D., Menting, S.P., Eidsmo, L., et al. (2014) Composition of Innate Lymphoid Cell Subsets in the Human Skin: Enrichment of $\mathrm{NCR}^{+}$ ILC3 in Lesional Skin and Blood of Psoriasis Patients. Journal of Investigative Dermatology, 134, 2351-2360. https://doi.org/10.1038/jid.2014.146

[23] Bernink, J.H., Peters, C.P., Munneke, M., te Velde, A.A., Meijer, S.L., Weijer, K., Hreggvidsdottir, H.S., Heinsbroek, S.E., Legrand, N., Buskens, C.J., et al. (2013) Human Type 1 Innate Lymphoid Cells Accumulate in Inflamed Mucosal Tissues. Nature Immunology, 14, 221-229. https://doi.org/10.1038/ni.2534

[24] Tang, M.L.K., Steeber, D.A., Zhang, X.-Q. and Tedder, T.F. (1998) Intrinsic Differences in L-Selectin Expression Levels Affect T and B Lymphocyte Subset-Specific Recirculation Pathways. Journal of Immunology, 160, 5113-5121.

[25] Yang, S., Liu, F., Wang, J.W., Rosenberg, S.A. and Morgan, R.A. (2011) The Shedding of CD62L (L-Selectin) Regulates the Acquisition of Lytic Activity in Human Tumor Reactive T Lymphocytes. PLoS ONE, 6, e22560.

https://doi.org/10.1371/journal.pone.0022560

[26] Mason, G.M., Lowe, K., Melchiotti, R., et al. (2015) Phenotypic Complexity of the Human Regulatory T Cell Compartment Revealed by Mass Cytometry. Journal of Immunology, 195, 2030-2037. https://doi.org/10.4049/jimmunol.1500703

[27] Chesnaye, N.C., van Stralen, J.K., Bonthuis, M., Groothoff, J.W., Harambat, J., Schaefer, F., Canpolat, N., Garnier, A., Heaf, J. and de Jong, H. (2017) Recipients in a European Society for Paediatric Nephrology/European Renal Association-European Dialysis and Transplantation Association Registry Study. Nephrology Dialysis Transplantation, 32, 1949-1956. https://doi.org/10.1093/ndt/gfx261

[28] Chavalitdhamrong, D., Gill, J., Takemoto, S., Madhira, B.R., Cho, Y.W., Shah, T. and Bunnapradist, S. (2008) Patient and Graft Outcomes from Deceased Kidney Donors Age 70 Years and Older: An Analysis of the Organ Procurement Transplant Network/United Network of Organ Sharing Database. Transplantation, 85, 1573-1579. https://doi.org/10.1097/TP.0b013e31817059a1

[29] Waiser, J., Schreiber, M., Budde, K., Fritsche, L., Bohler, T., Hauser, I. and Neumayer, H.H. (2000) Age-Matching in Renal Transplantation. Nephrology Dialysis Transplantation, 15, 696-700. https://doi.org/10.1093/ndt/15.5.696

[30] Lee, S.H., Oh, C.K., Shin, G.T., Kim, H., Kim, S.J. and Kim, S.I. (2014) Age Matching Improves Graft Survival after Living Donor Kidney Transplantation. Trans- 
plantation Proceedings, 46, 449-453.

https://doi.org/10.1016/j.transproceed.2013.10.049

[31] Chiu, B.C., Stolberg, V.R. and Chensu, S.W. (2007) Age-Related Loss of CD62L Impairs Lymph Node CD4 T Cell Mobilization. Open Longevity Science, 1, 1-7. https://doi.org/10.2174/1874369200701010001

[32] Merino, D., Segundo, D.S., Medina, J.M., Rodrigo, E., Asensio, E., Irure, J., FernándezFresnedo, G., Arias, M.A. and López-Hoyos, M. (2016) Different in Vitro Proliferation and Cytokine-Production Inhibition of Memory T Cell Subsets after Calcineurin and mTOR Inhibitors Treatment. Immunology, 148, 206-215.

https://doi.org/10.1111/imm.12603

[33] Nasimudeen, R., Francis, S., Sreelatha, M. and Puthenparambath, S. (2019) Comparison of Tacrolimus and Sirolimus Based Regimens on Regulatory T Cell Levels in Renal Transplant Recipients: A Study from a Tertiary Care Centre in Kerala, India. India Journal of Clinical and Diagnostic Research, 13, EC01-EC03. https://doi.org/10.7860/JCDR/2019/42355.13190

[34] Han, J.W., Joo, D.J., Kim, J.H., Rha, M.-S., Koh, J.Y., Park, H.J., Lee, J.G., Kim, M.S., Kim, S., Shin, E.C., Park, J.Y. and Park, S.H. (2020) Early Reduction of Regulatory T Cells Is Associated with Acute Rejection in Liver Transplantation under Tacrolimus-Based Immunosuppression with Basiliximab Induction. American Journal of Transplantation, 20, 2058-2069.

[35] Voortman, M.M., Greiner, P. and Mose, D.D. (2018) The Effect of Disease Modifying Therapies on CD62L Expression in Multiple Sclerosis. Multiple Sclerosis Journal-EXperimental, Translational and Clinical, 4. https://doi.org/10.1177/2055217318800810

[36] Gallon, L., Traitanon, O., Yu, Y., Shi, B., Leventhal, J.R., Miller, J., Mas, V. and Mathew, J.M. (2015) Differential Effects of Calcineurin and Mammalian Target of Rapamycin Inhibitors on Alloreactive Th1, Th17, and Regulatory T Cells. Transplantation, 99, 1774-1784. https://doi.org/10.1097/TP.0000000000000717

[37] Issa, F., Hester, J., Goto, R., Nadig, S.N., Goodacre, T.E. and Wood, K. (2010) EX Vivo-Expanded Human Regulatory T Cells Prevent the Rejection of Skin Allografts in a Humanized Mouse Model. Transplantation, 90, 1321-1327. https://doi.org/10.1097/TP.0b013e3181ff8772

[38] Mathew, J.M., Jessica, H.V., LeFever, A., et al. (2018) A Phase I Clinical Trial with ex Vivo Expanded Recipient Regulatory T Cells in Living Donor Kidney Transplants. Scientific Reports, 8, Article No. 7428.

https://doi.org/10.1038/s41598-018-25574-7 